\title{
Editorial
}

\section{A 2019 New Year's Resolution to Consider}

\author{
Patrick Carley \\ School of Health Sciences, American International College, USA \\ *Corresponding Author: Patrick Carley, School of Health Sciences, American International College, USA, \\ Tel: +413-205-3294; E-mail: Patrick.Carley@aic.edu
}

Received Date: 26 November, 2018; Accepted Date: 27 November, 2018; Published Date: 30 November 18

As I slowly begin to acknowledge the twilight of my career in both the physical rehabilitation of patients and the teaching of physical therapy students, I realize that things are changing in a very different direction than I previously thought in academia. We debate ways for program and student assessment entwined with heated debates on various pedagogical strategies. The effort challenges us to figure out how much and to what degree students learn. An older professor who mentored me some years ago constantly reminded me, "it is not important what you say, however, it is important as to what the students hear."

One of the graduate courses that I have been teaching for the past 29 years is Gross Anatomy Human Dissection. The other two courses part of my long-term instructional career are Kinesiology and Exercise Physiology. I can assure you that I have been challenged to think about diverse methods to engage students in the study of muscles, structure, and function. It seems that not so long ago that we were using overhead projectors and flimsy transparent sheets to demonstrate basic concepts essential in our course content.

No sooner said and we suddenly found ourselves embracing the wonderful world of PowerPoints, vivid pictures, diagrams, and even embedded videos. It was an exciting change from those old overheads. It was certainly needed to address the generation of learners who came before us. We quickly found new ways to reveal how bones and muscles work in finer detail. It was a fascinating new way of getting complicated concepts across with seemingly little effort.

Today, things are changing, and I seem to be consciously frustrated with PowerPoint slides.

Even the gold standard of learning bones and muscles, human dissection, appears to be losing its academic appeal to incentivize learning. This newest generation demands new pedagogies to get concepts of muscles and function information transitioned to knowledge. There seems to be an evolution underway and desperately sought by students. It is apparent that this new generation learns very differently and as a result, we must actively participate in this change once again reshaping our approaches to instructional methods and even in disseminating our own research.

The basis for this change is that these contemporary students grew up with a "screen" in front of them constantly through their waking hours. Tablets, iPads, computer screens, cell phones, and yes, a trip to the grocery store has a screen for children to watch something even on that short ride. We cannot even back up in our cars without the screen display on our dashboards. From that perspective, we have all become "screen agers" constantly checking our cell phones for any new information that may come our way.

My own research agenda has morphed to the use of wearable technology and virtual reality better understanding how we get patients to participate better in recovery. More importantly, how do we get future physical and occupational therapy students to use technology more effectively in future rehabilitative applications. Today's students are much better at visualizing muscle limitations and how to design more engaging exercise routines. Visualizing concepts in education is as radical as PowerPoints were back in the 1990's for engaging students. Just like learning PowerPoint was somewhat difficult initially but ultimately rewarding. Thinking of sharing information in more visualizing concepts will also be an uncomfortable transition but again, just as rewarding in the future.

As my own research evolves, I realize that for 2019, we need to think about how we write and present own research findings in future articles for the Journal of Bones and Muscles Study. In sharing what we have found with each other for 2019, we should consider those descriptions in a more visual way. When disseminating our findings, we should embrace it with the idea that we have all become "screen agers" and contemplate including more pictorial concepts of our work to make this a more unique and contemporary journal. Because, in the end, it is not important as to how we share our knowledge, it is how and what our readers take away from that shared journal experience. 


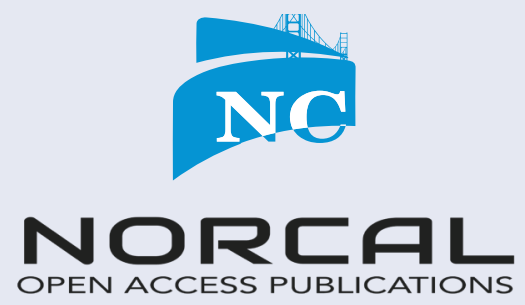

submit your manuscripts at

www. norcaloa.com 